\title{
USULAN PERBAIKAN PENGENDALIAN KUALITAS PRODUK DENGAN METODE SIX SIGMA PADA PEMBUATAN LABEL $X$ DI PT. BPP
}

\author{
Tri widodo \\ Mahasiswa Program Magister Teknik Industri, Program Pascasarjana \\ Universitas Mercu Buana, Jakarta-Indonesia \\ Tiga_wd@yahoo.co.id
}

\begin{abstract}
Competition in the corporate world these days of tighter encourage companies to further develop ideas for an effective and efficient in achieving the goals and objectives have been set. Label X is one of the products produced by PT. BPP. For blinding Label X companies also strive to continuously improve product quality by suppressing the number of defects in the production process.

Six Sigma is a vision of improved quality to the target 3.4 failures per million opportunities for each transaction of goods and services. So Six Sigma is a method or technique of controlling and improving the quality of which is a dramatic breakthrough in the field of quality management.

By using Six Sigma methods can be seen that the quality of label X produced by the company that is pretty good with the 2.79 sigma level of damage to 99.179 million production (DPMO). Implementation of six sigma quality improvement in this study can be concluded that there were three highest causes of product defects: color blur $82 \%$, did not register $9 \%$ and cutting $9 \%$.
\end{abstract}

Key Word : Label X, Six Sigma, DPMO

\section{PENDAHULUAN}

Dalam krisis 1998 banyak industri yang gagal bertahan, akibat menurunnya daya beli yang mengakibatkan turunnya permintaan dari produk masing-masing bidang industri. Tetapi, meskipun secara keseluruhan industri mengalami penurunan, industri di bidang costumer goods atau makanan merupakan salah satu industri yang dapat bertahan, karena produk makanan merupakan produk primer yang tetap dibutuhkan pasar dalam kondisi apapun. Hal inilah yang menjadikan industri kemasan juga dapat bertahan, karena industri kemasan sebagian besar memproduksi kemasan untuk makanan.

Industri kemasan memiliki sub bidang yang cukup banyak, seperti paper packaging, corrugated box, cans packaging (pengemasan kaleng), dan lainnya. Tingkat kebutuhan dan ketersediaan dari masing-masing sub bidang juga berbeda. Meningkatnya kebutuhan plastik kemasan dari tahun-tahun sebelumnya, ditambah prediksi ke depan yang semakin meningkat akibat kebutuhan alternatif lain dari kemasan kertas yang semakin lama ketersediaan bahan bakunya semakin sedikit dan sulit karena bersumber dari hutan, menjadikan bertambahnya peluang di industri kemasan plastik khususnya flexible packaging.

Berbekal pengalaman di bidang printing yang dirintis sejak tahun 2005 hingga 2008 dengan menggunakan nama badan usaha PT. BENNY PUTRA PERKASA, resmi didirikan pada tahun 2009. Meskipun dalam perjalanan awalnya PT. BPP menggeluti bidang printing yang cukup luas yang menggabungkan bidang printing dengan beberapa bidang lainnya seperti, promotion \& advertising, labeling, packaging dan lainnya, akhirnya PT. BPP memutuskan bergerak di bidang printing packaging khususnya flexible packaging.

PT. BPP memiliki motto "quality, quality, quality" sehingga kualitas menjadi sangat penting dalam memilih produk disamping faktor harga yang bersaing. Perbaikan dan peningkatan kualitas produk dengan harapan tercapainya tingkat cacat produk mendekati zero defect membutuhkan biaya yang tidak sedikit. Perbaikan kualitas dan perbaikan proses terhadap sistem produksi secara menyeluruh harus dilakukan jika perusahaan ingin menghasilkan produk yang berkualitas baik dalam waktu yang relatif singkat. Suatu perusahaan dikatakan berkualitas bila perusahaan tersebut mempunyai sistem produksi yang baik dengan proses terkendali. Melalui pengendalian kualitas (quality control) diharapkan bahwa perusahaan dapat meningkatkan efektifitas pengendalian dalam mencegah terjadinya produk cacat (defect prevention), sehingga dapat menekan terjadinya pemborosan dari segi material maupun tenaga kerja yang akhirnya dapat meningkatkan produktifitasPermasalahan yang dihadapi olah PT. BPP adalah kecacatan yang dihasilkan dari proses produksi. Dimana tingkat kecacatan melebihi batas maksimal yang ditargetkan adalah sebesar $2 \%$. Berikut gambar 1.1 menunjukan cacat produksi di PT. BPP setiap bulan mulai bulan Juli-Desember 2012. 


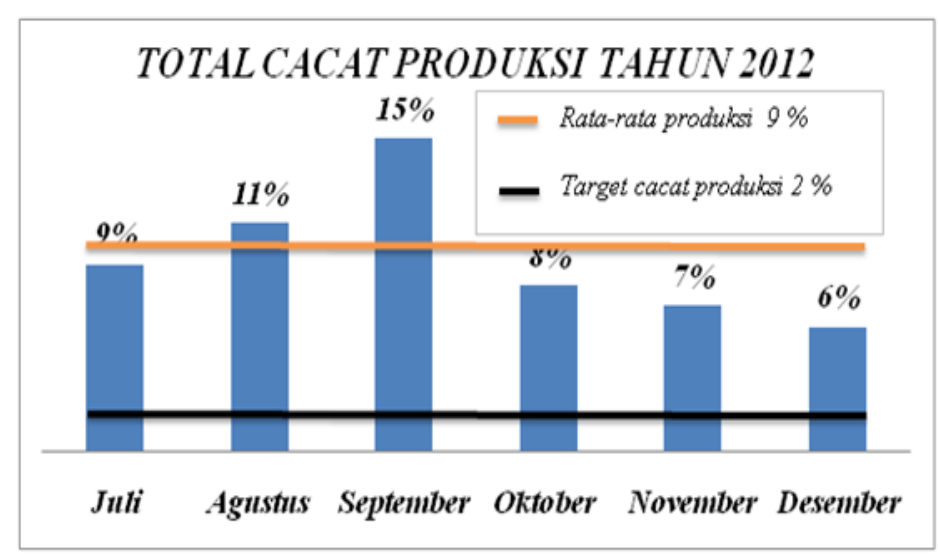

Gambar 1.1. Total cacat produksi tahun 2012

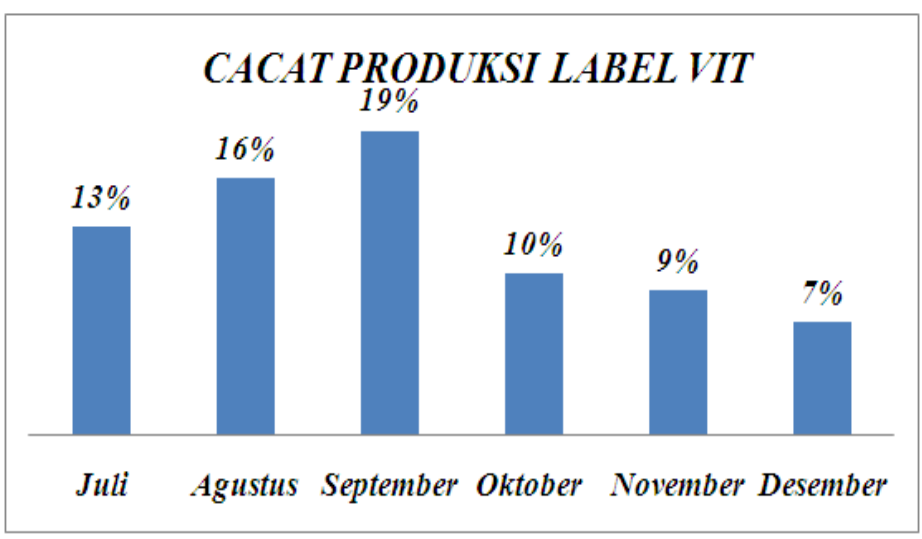

Gambar 1.2. Cacat produksi label vit

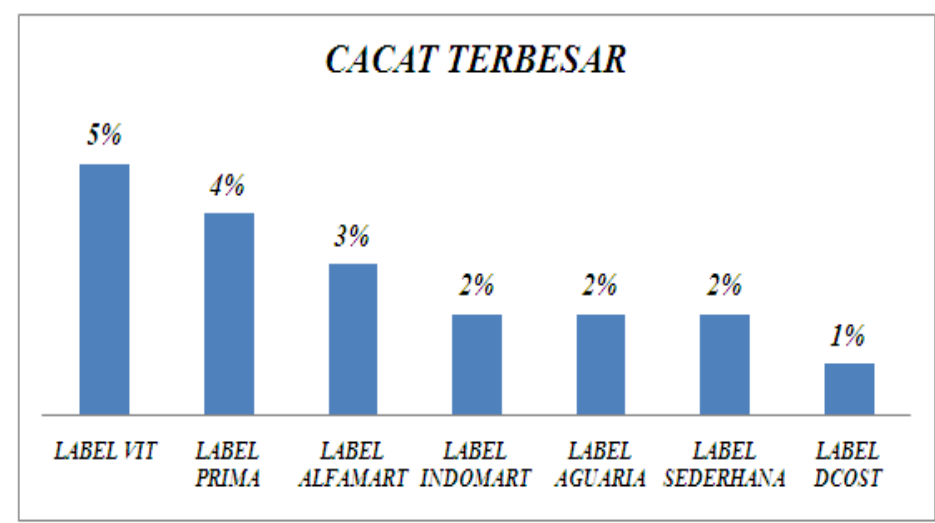

Gambar 1.3. Cacat terbesar

\section{RUMUSAN MASALAH}

Berkenaan dengan deskripsi di atas, masalah dalam penelitian ini adalah :

Faktor-faktor apa saja yang menyebabkan terjadinya produk cacat sehingga menyebabkan menurunnya tingkat kualitas?

Bagaimana implementasi pengendalian kualitas dengan menggunakan metode six sigma?

\section{Tujuan Penelitian}

Sesuai dengan rumusan masalah yang telah dikemukakan, maka tujuan dari penelitian ini adalah :

Menganalisa faktor-faktor penyebab terjadinya produk produk cacat pada proses produksi.

Menganalisis serta pengimplementasian usulan pengendalian kualitas dengan menggunakan metode six sigma.

\section{Batasan Masalah}

Pembatasan masalah pada menulisan tesis ini dilakukan dengan tujuan agar pokok masalah yang diteliti tidak melebar dari topic yang sudah ditentukan. Oleh karena itu dalam penyusunan tesis ini batasan masalah yang diberikan adalah sebagai berikut :

1. Penelitian dilakukan hanya pada produk label $X$.

2. Pengambilan data pada bulan September tahun 2012

3. Tahap Improve hanya sebatas usulan pada pihak perusahaan

4. Tahap Control dilakukan oleh perusahaan

\section{Landasan teori}

Six sigma adalah bertujuan yang hampir sempurna dalam memenuhi persyaratan pelanggan. Menurut (Gaspersz, 2005:310) six sigma adalah suatu visi peningkatan kualitas menuju target 3,4 kegagalan per sejuta kesempatan untuk setiap transaksi produk barang dan jasa. Jadi six sigma merupakan suatu metode atau teknik pengendalian dan peningkatan kualitas dramatik yang merupakan terobosan baru dalam bidang manajemen kualitas.

Pada dasarnya pelanggan akan merasa puas apabila mereka menerima nilai yang diharapkan mereka. Apabila produk diproses pada tingkat kualitas Six Sigma, maka perusahaan boleh mengharapkan 3,4 kegagalan per sejuta kesempatan atau mengharapkan bahwa 99,99966 persen dari apa yang diharapkan pelanggan akan ada dalam produk itu. Dan terdapat enam aspek kunci yang perlu diperhatikan dalam aplikasi konsep Six Sigma, yaitu :

1. Identifikasi pelanggan

2. Identifikasi produk

3. Identifikasi kebutuhan dalam memeroduksi produk untuk pelanggan

4. Definisi proses

5. Menghindari kesalahan dalam proses dan menghilangkan semua pemborosan yang ada

6. Tingkatkan proses secara terus menerus menuju target Six Sigma

Menurut (Gaspersz, 2005:310) apabila konsep Six sigma akan ditetapkan dalam bidang manufakturing, terdapat enam aspek yang perlu diperhatikan yaitu:

1. Identifikasi karakteristik produk yang memuaskan pelanggan (sesuai kebutuhan dan ekspetasi pelanggan).

2. Mengklasifikasikan semua karakteristik kualitas itu sebagai CTQ (Critical-To-Quality) individual 
3. Menentukan apakah setiap CTQ tersebut dapat dikendalikan melalui pengendalian material, mesin proses kerja dan lainlain.

4. Menentukan batas maksimum toleransi untuk setiap CTQ sesuai yang diinginkan pelanggan (menentukan nilai UCL dan LCL dari setiap CTQ).

5. Menentukan maksimum variasi proses untuk setiap CTQ (menentukan nilai maksimum standar deviasi untuk setiap CTQ ).

6. Mengubah desain produk dan / atau proses sedemikian rupa agar mampu mencapai nilai target Six Sigma.

Tahap-Tahap Implementasi Pengendalian Kualitas dengan Six Sigma

\section{A. Define}

Define adalah penetapan sasaran dari aktiXas peningkatan kualitas Six Sigma. Langkah ini untuk mendefinisikan rencanarencana tindakan yang harus dilakukan untuk melaksanakan peningkatan dari setiap tahap proses bisnis kunci. tiga aktiXas utama yang berkaitan dengan mendefinisikan proses inti dan para pelanggan adalah

1. Mendefinisikan proses inti mayor dari bisnis.

2. Menentukan output kunci dari proses inti tersebut, dan para pelanggan kunci yang mereka layani.

3. Menciptakan peta tingkat tinggi dari proses inti atau proses strategis

\section{B. Measure}

Measure merupakan tindak lanjut logis terhadap langkah define dan merupakan sebuah jembatan untuk langkah berikutnya

Measure merupakan langkah oprasional yang kedua dalam program peningkatan kualitas Six Sigma. Terdapat tiga hal pokok yang harus dilakukan, yaitu:

1. Memilih atau menentukan karakteristik kualitas (Critical to Quality) kunci.

2. Mengembangkan rencana pengumpulan data

3. Pengukuran baseline kinerja pada tingkat output

C. Analyze

Merupakan langkah operasional yang ketiga dalam program peningkatan kualitas six sigma

1. Menentukan stabilitas dan kemampuan ( kapabilitas) proses

2. Menetapkan target kinerja dari karakteristik kualitas (CTQ) kunci

3. Mengidentifikasi sumber-sumber dan akar penyebab masalah kualitas.

\section{Improve}

Pada langkah ini diterapkan suatu rencana tindakan untuk melaksanakan peningkatan kualitas Six sigma. Rencana tersebut mendeskripsikan tentang alokasi sumber daya serta prioritas atau alternatif yang dilakukan

\section{E. Control}

Control merupakan tahap operasional terakhir dalam upaya peningkatan kualitas berdasarkan Six Sigma. Pada tahap ini hasil peningkatan kualitas didokumentasikan dan disebarluaskan, praktik-praktik terbaik yang sukses dalam peningkatan proses distandarisasi dan disebarluaskan, prosedur didokumentasikan dan dijadikan sebagai pedoman standar, serta kepemilikan atau tanggung jawab ditransfer dari tim kepada pemilik atau penanggung jawab proses

\section{Metodologi penelitian}

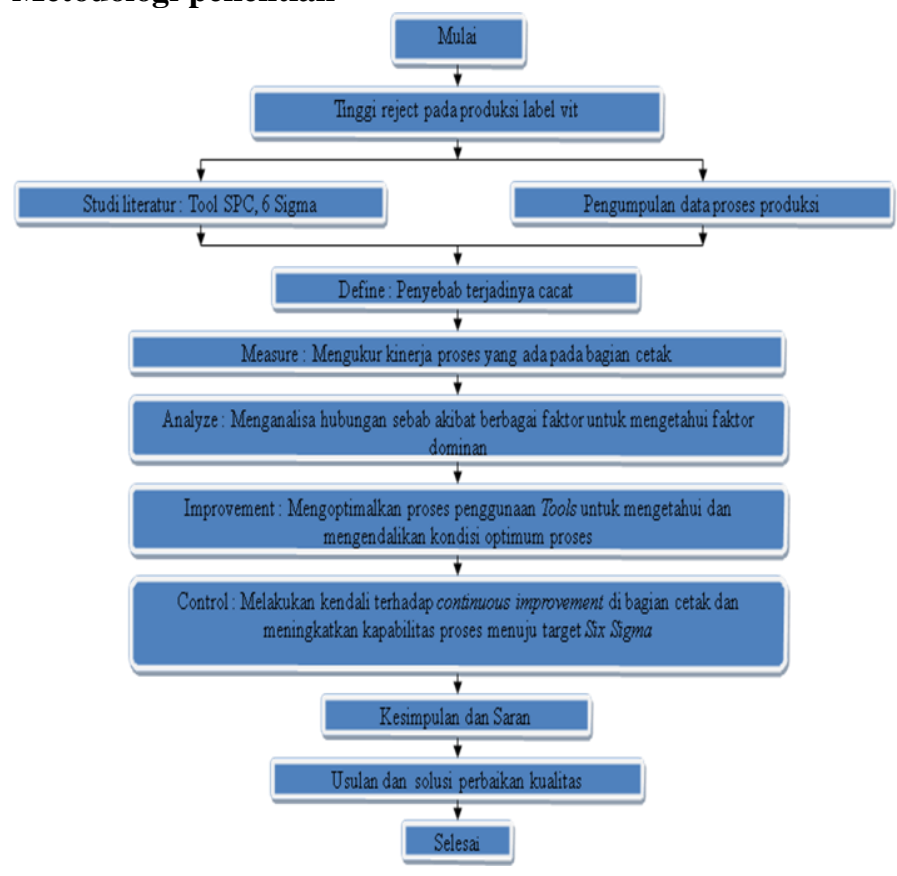

\section{Data \& Analisa}

\section{a. Define}

Fase define merupakan fase awal dalam tahapan DMAIC. Tahapan pada fase ini adalah dengan mengukur produk yang menentukan gambaran dari proses produksi yang berlangsung dengan diagram input - proses - output, dan menentukan CTQ (Critical To Quality) produk, dimana fase define terbagi :

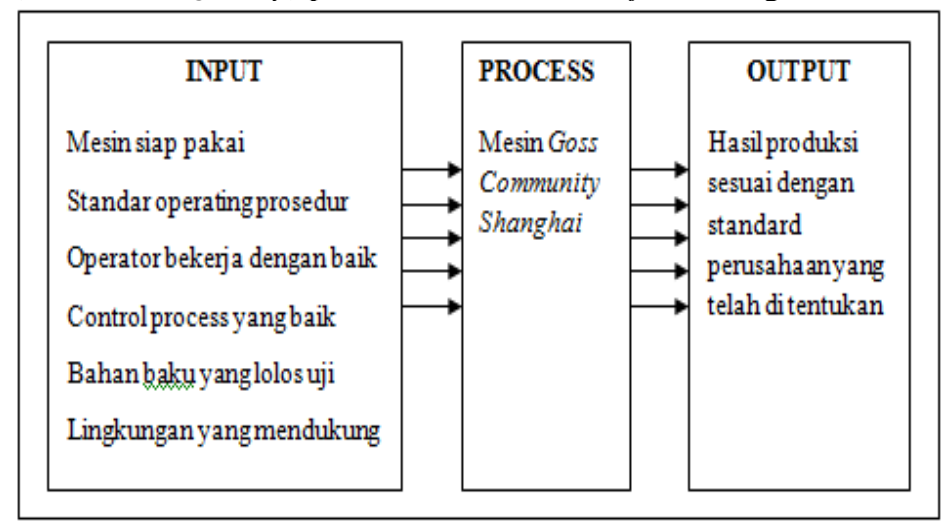

Gambar 4.2.

Diagram IP0 (Input-Proses-Output) 
Tabel 4.1.

Penentuan CTQ (Critical To Quality)

\begin{tabular}{|c|l|l|l|}
\hline \multirow{2}{*}{$\begin{array}{c}\text { Persyaratan } \\
\text { Output }\end{array}$} & \multicolumn{2}{|c|}{ Kebutuhan Pelanggan } & \multicolumn{1}{c|}{ Matriks Kinerja } \\
\cline { 2 - 4 } & Dimensi & \multicolumn{1}{|c|}{$\begin{array}{c}\text { Karakteristik } \\
\text { kualitas (CTQ) }\end{array}$} & \multicolumn{1}{c|}{ Internal } \\
\hline \multirow{4}{*}{$\begin{array}{c}\text { Produk } \\
\text { berkualitas }\end{array}$} & Pengoprasian & $\begin{array}{l}\text { Mudah diproses di } \\
\text { mesin }\end{array}$ & $\begin{array}{l}\text { Desain produk yang } \\
\text { teruji dimensi dengan } \\
\text { ketelitian dan ukuran } \\
\text { yang sesuai pemesanan }\end{array}$ \\
\cline { 2 - 4 } & Ketahanan & Tidak mudah sobek & $\begin{array}{l}\text { Desain produk yang } \\
\text { tepat menggunakan } \\
\text { material yang sesuai }\end{array}$ \\
\cline { 2 - 4 } & Visual & $\begin{array}{l}\text { Penampilan produk } \\
\text { yang baik }\end{array}$ & $\begin{array}{l}\text { Proses yang tepat untuk } \\
\text { memastikan tidak } \\
\text { adanya cacat pada } \\
\text { produk }\end{array}$ \\
\cline { 2 - 4 } & $\begin{array}{l}\text { Ketepatan } \\
\text { waktu } \\
\text { pengiriman }\end{array}$ & $\begin{array}{l}\text { Sesuai dengan } \\
\text { deadline pelanggan }\end{array}$ & $\begin{array}{l}\text { Penjadwalan } \\
\text { pengiriman yang tepat }\end{array}$ \\
\cline { 2 - 4 } & Harga & Harga kompetitif & $\begin{array}{l}\text { Proses produksi yang } \\
\text { baik dengan } \\
\text { pengawasan yang tepat }\end{array}$ \\
\hline
\end{tabular}

Define merupakan tahap pendefinisian masalah kualitas dalam produk label $\mathrm{X}$, pada tahap ini yang menjadikan produk mengalami cacat didefinisikan penyebabnya. Dengan berdasarkan pada permasalahan yang ada, 3 penyebab produk cacat tertinggi dapat didefinisikan yaitu : warna kabur, tidak register, dan terpotong melebihi garis tepi.

\section{b. Measure}

Dalam melakukan pengendalian kualitas secara statistik, langkah pertama yang akan dilakukan adalah membuat check sheet. Check sheet berguna untuk mempermudah proses pengumpulan data serta analisis

Tabel 4.2

Laporan Produksi Label X Selama Bulan September 2012

\begin{tabular}{|c|c|c|c|c|c|c|}
\hline \multirow[b]{2}{*}{ Tanggal } & \multirow{2}{*}{$\begin{array}{c}\text { Jumlah Produksi } \\
\text { (exp) }\end{array}$} & \multicolumn{3}{|c|}{ Jenis Cacat (exp) } & \multirow{2}{*}{$\begin{array}{l}\text { Jumlah Produk } \\
\text { Cacat (exp) }\end{array}$} & \multirow{2}{*}{$\begin{array}{c}\text { Persentase Produk } \\
\text { Cacat (\%) }\end{array}$} \\
\hline & & Kabur & $\begin{array}{c}\text { Tidak } \\
\text { Register }\end{array}$ & Terpotong & & \\
\hline 1 & 53250 & 4236 & 489 & 592 & 5317 & 10,0 \\
\hline 2 & 53250 & 4261 & 467 & 421 & 5149 & 9,7 \\
\hline 3 & 51500 & 4074 & 403 & 402 & 4879 & 9,5 \\
\hline 4 & 51500 & 4026 & 408 & 404 & 4838 & 9,4 \\
\hline 5 & 55750 & 4598 & 632 & 426 & 5656 & 10,1 \\
\hline 6 & 53250 & 4311 & 452 & 480 & 5243 & 9,8 \\
\hline 7 & 53250 & 4291 & 474 & 452 & 5217 & 9,8 \\
\hline 8 & 53250 & 4227 & 456 & 431 & 5114 & 9,6 \\
\hline 9 & 53250 & 4278 & 498 & 476 & 5252 & 9,9 \\
\hline 10 & 51800 & 4013 & 414 & 426 & 4853 & 9,4 \\
\hline 11 & 51800 & 4059 & 421 & 422 & 4902 & 9,5 \\
\hline 12 & 56118 & 4323 & 824 & 817 & 5964 & 10,6 \\
\hline 13 & 53550 & 4371 & 487 & 476 & 5334 & 10,0 \\
\hline 14 & 53550 & 4363 & 579 & 463 & 5405 & 10,1 \\
\hline 15 & 53550 & 4392 & 466 & 411 & 5269 & 9,8 \\
\hline 16 & 53550 & 4365 & 462 & 416 & 5243 & 9,8 \\
\hline 17 & 51800 & 4026 & 418 & 429 & 4873 & 9,4 \\
\hline 18 & 51800 & 4023 & 428 & 428 & 4879 & 9,4 \\
\hline 19 & 56000 & 4769 & 689 & 673 & 6131 & 10,9 \\
\hline 20 & 53550 & 4467 & 498 & 465 & 5430 & 10,1 \\
\hline 21 & 53550 & 4432 & 493 & 459 & 5384 & 10,1 \\
\hline 22 & 53550 & 4397 & 498 & 462 & 5357 & 10,0 \\
\hline 23 & 53550 & 4320 & 482 & 442 & 5244 & 9,8 \\
\hline 24 & 52000 & 4367 & 486 & 439 & 5292 & 10,2 \\
\hline 25 & 52000 & 4362 & 470 & 479 & 5311 & 10,2 \\
\hline TOTAL & 1329968 & 107351 & 12394 & 11791 & 131536 & 247 \\
\hline $\begin{array}{l}\text { RATA- } \\
\text { RATA }\end{array}$ & 53199 & 4294 & 496 & 472 & 5261 & 10 \\
\hline
\end{tabular}

1. Analisis Diagram Kontrol (P-Chart)

Menghitung mean $(C L)$ atau rata-rata produk akhir yaitu :

$C L=\sum n p / \sum n$

$C L=131536 / 1329968=0.099$

$P=n p / n$

Tanggal $1 \quad: \mathrm{P}=5317 / 53250=0.100$

Menghitung batas kendali atas atau Upper Control Limit (UCL), untuk menghitung batas kendali atas atau UCL dilakukan dengan rumus :

$\mathrm{UCL}=\mathrm{CL}+\sqrt[\sqrt[a]{C L(1-C L)}]{\mathrm{n}}$

Tanggal $1 \quad: 0,099+\frac{\sqrt[a]{C L(1-C L)}}{n}=0,111$

Menghitung batas kendali atas atau Lower Control Limit (LCL), untuk menghitung batas kendali atas atau LCL dilakukan dengan rumus :

$$
\mathrm{LCL}=\mathrm{CL}-\frac{\sqrt[s]{C L(1-C L)}}{\mathrm{n}}
$$

Tanggal $1 \quad: 0,099-\sqrt[8]{C L(1-C L)}=0,087$

Tabel 4.3

Perhitungan Batas Kendali Label X Selama Bulan September

\begin{tabular}{|c|c|c|c|c|c|c|} 
Tangga & Jumlah \\
$\boldsymbol{l}$ & $\begin{array}{c}\text { Jumlah } \\
\text { Produksi (exp) }\end{array}$ & $\begin{array}{c}\text { Persentase } \\
\text { Produk Cacat }\end{array}$ & $\begin{array}{c}\text { Cacat } \\
\text { CI }\end{array}$ & UCI & LCI \\
\hline 1 & 53250 & 5317 & 10,0 & 0,099 & 0,111 & 0,087 \\
\hline 2 & 53250 & 5149 & 9,7 & 0,099 & 0,111 & 0,087 \\
\hline 3 & 51500 & 4879 & 9,5 & 0,099 & 0,111 & 0,087 \\
\hline 4 & 51500 & 4838 & 9,4 & 0,099 & 0,111 & 0,087 \\
\hline 5 & 55750 & 5656 & 10,1 & 0,099 & 0,111 & 0,087 \\
\hline 6 & 53250 & 5243 & 9,8 & 0,099 & 0,111 & 0,087 \\
\hline 7 & 53250 & 5217 & 9,8 & 0,099 & 0,111 & 0,087 \\
\hline 8 & 53250 & 5114 & 9,6 & 0,099 & 0,111 & 0,087 \\
\hline 9 & 53250 & 5252 & 9,9 & 0,099 & 0,111 & 0,087 \\
\hline 10 & 51800 & 4853 & 9,4 & 0,099 & 0,111 & 0,087 \\
\hline 11 & 51800 & 4902 & 9,5 & 0,099 & 0,111 & 0,087 \\
\hline 12 & 56118 & 5964 & 10,6 & 0,099 & 0,111 & 0,087 \\
\hline 13 & 53550 & 5334 & 10,0 & 0,099 & 0,111 & 0,087 \\
\hline 14 & 53550 & 5405 & 10,1 & 0,099 & 0,111 & 0,087 \\
\hline 15 & 53550 & 5269 & 9,8 & 0,099 & 0,111 & 0,087 \\
\hline 16 & 53550 & 5243 & 9,8 & 0,099 & 0,111 & 0,087 \\
\hline 17 & 51800 & 4873 & 9,4 & 0,099 & 0,111 & 0,087 \\
\hline 18 & 51800 & 4879 & 9,4 & 0,099 & 0,111 & 0,087 \\
\hline 19 & 56000 & 6131 & 10,9 & 0,099 & 0,111 & 0,087 \\
\hline 20 & 53550 & 5430 & 10,1 & 0,099 & 0,111 & 0,087 \\
\hline 21 & 53550 & 5384 & 10,1 & 0,099 & 0,111 & 0,087 \\
\hline 22 & 53550 & 5357 & 10,0 & 0,099 & 0,111 & 0,087 \\
\hline 23 & 53550 & 5244 & 9,8 & 0,099 & 0,111 & 0,087 \\
\hline 24 & 52000 & 5292 & 10,2 & 0,099 & 0,111 & 0,087 \\
\hline 25 & 52000 & 5311 & 10,2 & 0,099 & 0,111 & 0,087 \\
\hline TOTAL & 1329968 & $\mathbf{1 3 1 5 3 6}$ & & & & \\
\hline & & & & & & \\
\hline
\end{tabular}




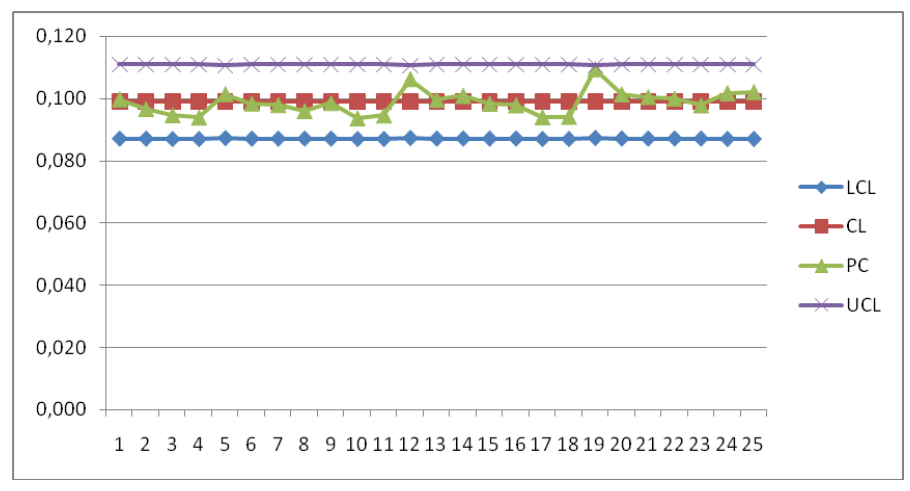

Gambar 4.3

Grafik Peta Kendali

Label X Selama Bulan September 2012

Tahap pengukuran tingkat Six Sigma dan Defect Per Million Opportunities (DPMO). Untuk mengukur tingkat Six Sigma dari hasil produksi label $\mathrm{X}$ dapat dilakukan dengan cara sebagai berikut:

Menghitung DPU (Defect Per Unit)

DPU $=\frac{\text { Total Kerusakan }}{\text { Total Produksi }}$

Menghitung DPMO (Defect Per Million Oportunities)

DPMO $=\frac{\text { Total Cacat Produksi }}{\text { Jumlah Produksi }} X 1.000 .000$

Mengkonversikan hasil perhitungan DPMO dengan tabel Six Sigma untuk mendapatkan hasil sigma.

Tabel 4.4

Pengukuran Tingkat Sigma Dan Defect Per Million Opportunities (DPMO) Selama September 2012

\begin{tabular}{|c|c|c|c|c|c|}
\hline Tanggal & Jumlah Produksi (exp) & Jumlah Produk & DPU & DPMO & NILAI SIGMA \\
\hline 1 & 53250 & 5317 & 0,100 & 99.850 & 2,78 \\
\hline 2 & 53250 & 5149 & 0,097 & 96.695 & 2,80 \\
\hline 3 & 51500 & 4879 & 0,095 & 94.738 & 2,81 \\
\hline 4 & 51500 & 4838 & 0,094 & 93.942 & 2,82 \\
\hline 5 & 55750 & 5656 & 0,101 & 101.453 & 2,77 \\
\hline 6 & 53250 & 5243 & 0,098 & 98.460 & 2,79 \\
\hline 7 & 53250 & 5217 & 0,098 & 97.972 & 2,79 \\
\hline 8 & 53250 & 5114 & 0,096 & 96.038 & 2,80 \\
\hline 9 & 53250 & 5252 & 0,099 & 98.629 & 2,80 \\
\hline 10 & 51800 & 4853 & 0,094 & 93.687 & 2,82 \\
\hline 11 & 51800 & 4902 & 0,095 & 94.633 & 2,81 \\
\hline 12 & 56118 & 5964 & 0,106 & 106.276 & 2,74 \\
\hline 13 & 53550 & 5334 & 0,100 & 99.608 & 2,79 \\
\hline 14 & 53550 & 5405 & 0,101 & 100.934 & 2,78 \\
\hline 15 & 53550 & 5269 & 0,098 & 98.394 & 2,79 \\
\hline 16 & 53550 & 5243 & 0,098 & 97.908 & 2,80 \\
\hline 17 & 51800 & 4873 & 0,094 & 94.073 & 2,82 \\
\hline 18 & 51800 & 4879 & 0,094 & 94.189 & 2,84 \\
\hline 19 & 56000 & 6131 & 0,109 & 109.482 & 2,73 \\
\hline 20 & 53550 & 5430 & 0,101 & 101.401 & 2,78 \\
\hline 21 & 53550 & 5384 & 0,101 & 100.542 & 2,78 \\
\hline 22 & 53550 & 5357 & 0,100 & 100.037 & 2,78 \\
\hline 23 & 53550 & 5244 & 0,098 & 97.927 & 2,80 \\
\hline 24 & 52000 & 5292 & 0,102 & 101.769 & 2,77 \\
\hline 25 & 52000 & 5311 & 0,102 & 102.135 & 2,77 \\
\hline TOTAL & 1329968 & 131536 & 2,471 & 2.470 .771 & 69,76 \\
\hline $\boldsymbol{R A T A - R A T A}$ & $\mathbf{5 3 1 9 9}$ & $\mathbf{5 2 6 1}$ & 0,099 & 98831 & 2,7904 \\
\hline & & & & & \\
\hline
\end{tabular}

c. Analyze

1. Diagram Pareto

Data yang diolah untuk mengetahui persentase jenis produk yang di tolak. Di hitung menggunakan rumus sebagai berikut :

$\%$ Kerusakan $=\frac{\text { Jumlah Kerusakan Jenis }}{\text { Jumlah Keruskan Keseluruhan }} X 100 \%$

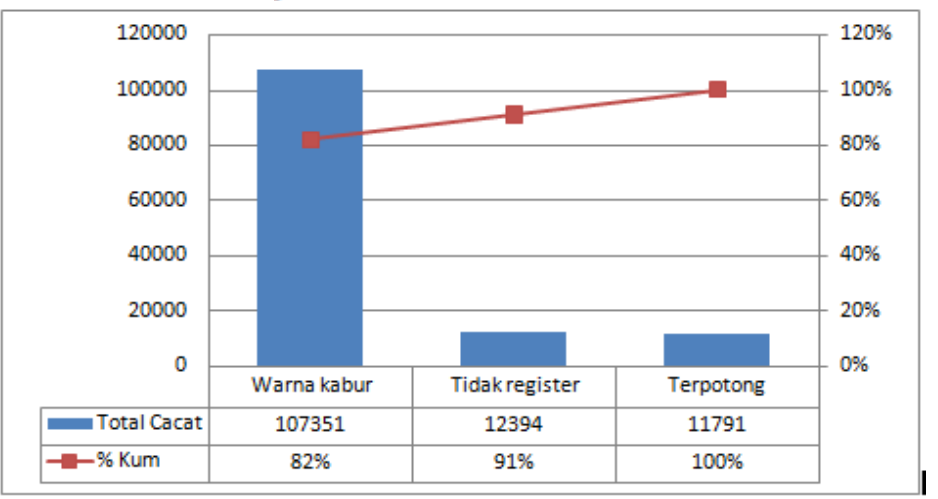

Gambar 4. 4

Diagram Pareto

Jenis Kecacatan Label Vit Selama Bulan September 2012 Warna Kabur

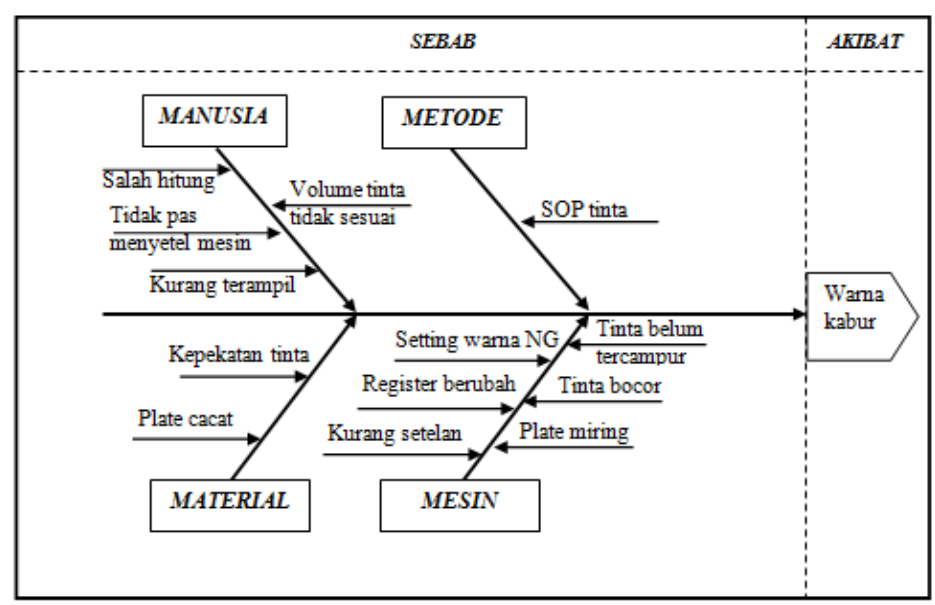

Gambar 4.5

Diagram Sebab-Akibat

Untuk jenis Kecacatan Warna Kabur

Hal ini disebabkan dari faktor-faktor sebagai berikut :

a. Faktor Mesin

Merupakan sebab utama yang mengakibatkan kerusakan jenis ini. Hal ini disebabkan oleh:

$>$ Setting persentase warna pada mesin yang kurang bagus.

$>$ Lapisan roll blanket yang lecet atau rusak dan pompa tinta rusak sehingga tinta mblobor atau luber.

$>$ Kurang meratanya tinta pada tanki warna mesin cetak dikarenakan volume tinta pada tanki warna yang kurang dan tinta yang masih terlalu pekat, sehingga penyerapan warna menjadi tidak merata.

$>$ Plate untuk cetak gambar miring. 
b. Faktor Manusia

$>$ Operator mengisi volume tinta pada tanki warna tidak sesuai takaran yang pas.

$>$ Operator mesin yang kurang cermat dalam menyetel kekencangan mesin sehingga perputarannya dapat mengganggu kestabilan register dan plate. Hal ini disebabkan oleh operator yang mungkin belum terampil atau berpengalaman dalam melakukan penyetelan yang pas dan juga karena salah perhitungan dalam menyetel kekencangan mesin.

c. Faktor Material

$>$ Tingkat kepekatan tinta yang berbeda-beda disinyalir juga merupakan penyebab dari kecacatan ini karena mengakibatkan percampuran untuk membuat suatu warna menjadi tidak merata.

> Adanya plate yang cacat atau rusak juga dapat mengakibatkan warna menjadi kabur karena tidak dapat dibaca secara sempurna oleh mesin.

d. Faktor Metode

$>$ Tidak adanya standar atau prosedur yang jelas mengenai takaran tinta yang sesuai akan menyulitkan pekerja ketika akan mengisi tinta kedalam mesin secara tepat.

Tidak Register

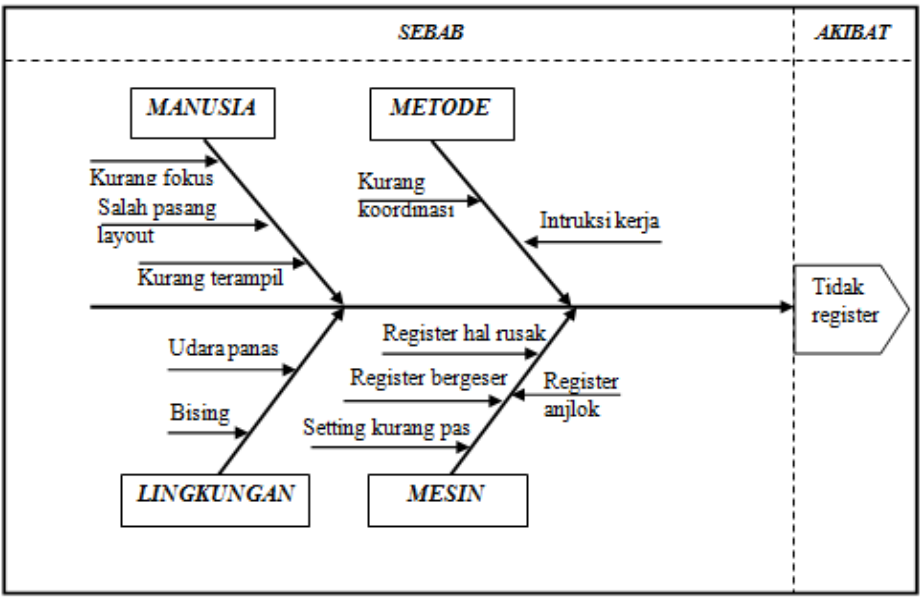

Gambar 4.6

Diagram Sebab-Akibat

Untuk jenis Kecacatan Tidak Register

a. Faktor Mesin

$>$ Register warna yang terdapat di dalam mesin anjlok.

$>$ Perputaran mesin yang cepat menjadikan register halaman bergeser.

$>$ Register halaman error karena settingan mesin yang tidak pas sehingga proses cetak tidak berjalan lancar.

$>$ Letak plate bergeser sehingga menjadikan layout label juga ikut tergeser.

b. Faktor Manusia

$>$ Pekerja yang kurang terampil dalam melakukan setting mesin dan register.
Kesalahan operator dalam memasang layout karena kurang teliti dan tidak fokus.

c. Faktor Metode

> Instruksi kerja yang tidak dipahami secara jelas oleh pekerja menjadikan pekerja melakukan kesalahan dan kelalaian.

$>$ Terjadinya kesalahan kerja karena kurangnya koordinasi antara bagian perencanaan cetak label dengan operator di lapangan mengenai penempatan layout dan settingan mesin.

d. Faktor Lingkungan

$>$ Suhu udara yang panas menjadikan pekerja kurang nyaman dalam melakukan pekerjaannya sehingga melakukan kesalahan.

$>$ Suara bising dari mesin sedikit banyak juga berpengaruh terhadap konsentrasi pekerja terutama sewaktu mengatur layout dan register yang membutuhkan ketelitian dan kecermatan.

Terpotong

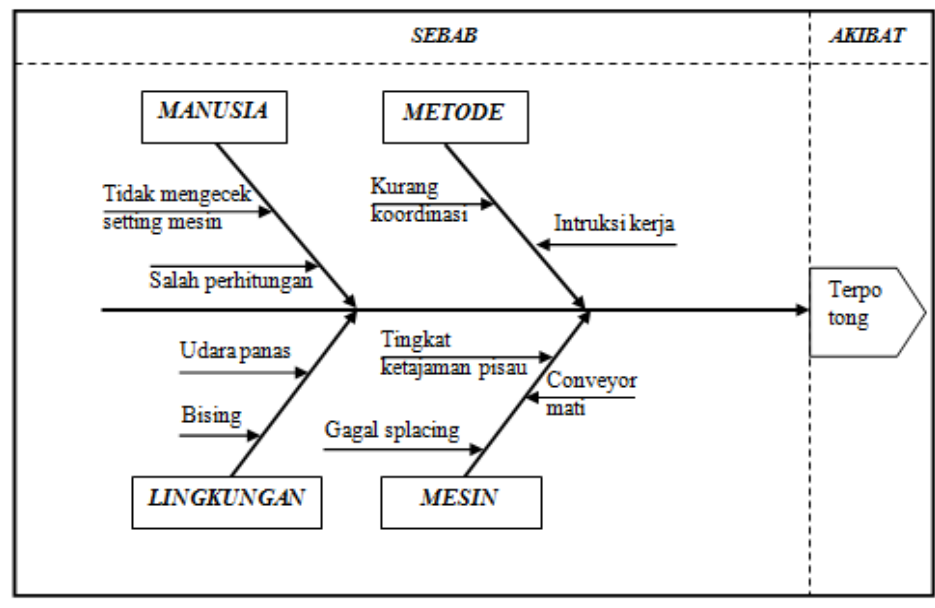

Gambar 4.7

Diagram Sebab-Akibat

Untuk jenis Kecacatan Terpotong

a) Faktor Mesin

$>$ Tingkat ketajaman pisau potong.

> Conveyor mesin macet/ rusak akan menyebabkan aliran distribusi label dari tahap pelipatan ke pemotongan menjadi terhambat sehingga menyebabkan banyak label yang terpotong tidak sesuai ukuran.

> Gagal splacing karena putaran roll plastik kurang kencang sehingga plastik yang terpotong tidak beraturan.

b) Faktor Manusia

$>$ Operator tidak teliti dalam mengecek kembali settingan mesin setelah sebelumnya digunakan.

> Kecerobohan dari operator dalam menjalankan mesin sehingga mesin terganggu dan conveyor mesin macet. 
Kesalahan dalam memperhitungkan perputaran mesin oleh operator sehingga perputaran mesin tidak beraturan dan distribusi plastik terganggu.

c) Faktor Metode

$>$ Kurangnya koordinasi antar operator dalam menjalankan mesin menyebabkan jalannya mesin terganggu.

d) Faktor Lingkungan

$>$ Suhu udara yang panas bisa mengganggu mood karyawan dalam bekerja.

> Suara bising dari mesin mengurangi fokus dari para operator dalam melakukan koordinasi dalam menjalankan mesin.

\section{d. Improve}

Merupakan rencana tindakan untuk melaksanakan peningkatan kualitas Six sigma. Setelah mengetahui penyebab kecacatan atas produk label X, maka disusun suatu rekomendasi atau usulan tindakan perbaikan secara umum dalam upaya menekan tingkat kerusakan produk sebagai berikut:

\section{Usulan Tindakan Untuk Jenis Kecacatan Warna Kabur} Manusia

$>$ Membuat suatu bagian kerja baru yang bertugas melakukan pengawasan dan pengecekan ulang terhadap kinerja karyawan sehingga dapat mengurangi kesalahan yang disebabkan oleh human error

> Meningkatkan pelatihan agar karywan lebih terampil dalam menjalankan tugas

Metode

$>$ Membuat daftar / kurva pembentukan warna abu-abu atau yang lebih sering disebut Grey Balance untuk menentukan standard ketebalan takaran tinta sehingga didapat hasil cetakan yang sesuai dengan warna yang dikehendaki.

Material

$>$ Memeriksa kembali bahan baku yang diterima dari pemasok dengan lebih teliti dan memeriksa apakah sudah memenuhi spesifikasi yang ditentukan atau tidak.

> Memisahkan bahan baku yang rusak/ mengalami cacat dengan bahan baku yang berkualitas baik

Mesin

$>$ Melakukan pengecekan kesiapan mesin dengan teliti sebelum digunakan dan juga ketika selesai digunakan.

$>$ Melakukan perawatan mesin secara rutin, tidak hanya dilakukan ketika mesin mengalami kerusakan (preventive maintenance).

$>$ Menyediakan suku cadang mesin yang penggantian kompenennya cukup sering agar tidak menghambat proses

\section{Usulan Tindakan Untuk Jenis Kecacatan Tidak Register \\ Manusia}

> Mengadakan program pelatihan bagi pekerja baik yang lama maupun yang baru secara berkala.

> Memberikan pengarahan dan peringatan kepada operator yang melalukan kesalahan
Metode

> Instruksi kerja diberikan secara tertulis dengan disertai penjelasan lisan secara terperinci yaitu dengan melaksanakan briefing secara rutin disetiap awal dan akhir kerja.

> Menggunakan peralatan komunikasi elektronik portable untuk melakukan komunikasi sehingga memudahkan dalam melakukan koordinasi antar pekerja dan tidak terganggu oleh suara bising mesin dan jarak antar pekerja yang saling berjauhan

Lingkungan

$>$ Menambah fasilitas diruang produksi untuk mengurangi dampak udara panas yang disebabkan oleh mesin dan cuaca misalnya dengan menambah kipas angin di setiap sudut.

$>$ Mewajibkan penggunaan alat pengaman telinga untuk memberikan ketenangan pekerja dalam proses produksi serta menjaga gendang telinga.

Mesin

$>$ Melakukan perawatan mesin secara rutin, tidak hanya dilakukan ketika mesin mengalami kerusakan (preventive maintenance).

> Melakukan pengecekan kesiapan mesin dengan teliti pada saat sebelum dan sesudah digunakan.

$>$ Menyediakan suku cadang mesin yang penggantian kompenennya cukup sering agar tidak menghambat proses produksi.

\section{Usulan Tindakan Untuk Jenis Kecacatan Terpotong}

Manusia

$>$ Membuat suatu bagian kerja baru yang bertugas melakukan pengawasan dan pengecekan ulang terhadap kinerja karyawan sehingga dapat mengurangi kesalahn yang disebabkan oleh human error.

$>$ Memberkan peringatan kepada pekerja apabila melakukan kesalahan.

> Memberikan sanksi kepada karyawan yang lalai sehingga dapat menghindari perbuatan yang sama di lain waktu.

Metode

> Menggunakan peralatan komunikasi elektronik portable untuk melakukan komunikasi sehingga memudahkan dalam melakukan koordinasi antar pekerja dan tidak terganggu oleh suara bising mesin dan jarak antar pekerja yang saling berjauhan.

Lingkungan

$>$ Menambah fasilitas diruang produksi untuk mengurangi dampak udara panas yang disebabkan oleh mesin dan cuaca misalnya dengan menambah kipas angin di setiap sudut.

$>$ Mewajibkan penggunaan alat pengaman telinga untuk memberikan ketenangan pekerja dalam proses produksi serta menjaga gendang telinga.

Mesin

> Melakukan pengecekan kesiapan mesin dengan teliti sebelum digunakan dan juga ketika selesai digunakan. 
Melakukan perawatan mesin secara rutin, tidak hanya dilakukan ketika mesin mengalami kerusakan (preventive maintenance).

$>$ Menyediakan suku cadang mesin yang penggantian kompenennya cukup sering agar tidak menghambat proses produksi

\section{e. Control}

Merupakan tahap analisis terakhir dari proyek six sigma yang menekankan pada pendokumentasian dan penyebarluasan dari tindakan yang telah dilakukan meliputi:

1. Melakukan perawatan dan perbaikan mesin secara berkala

2. Melakukan pengawasan terhadap bahan baku dan karyawan bagian produksi agar mutu barang yang dihasilkan lebih baik.

3. Melakukan pencatatan dan penimbangan seluruh produk catat setiap hari dari masing-masing jenis dan mesin, yang dilakukan oleh karyawan dalam proses produksi.

4. Melaporkan hasil penimbangan produk cacat berdasarkan type produk catat kepada supervisor.

5. Total produk cacat dalam periode satu bulan dicantumkan dalam montly manager. Scorecard atas pertanggung jawaban manajer produksi untuk dilaporkan presiden direktur

\section{Kesimpulan}

1. Jenis-jenis kerusakan atau misdruk yang sering terjadi pada produksi pembutan label $\mathrm{X}$ yaitu disebabkan karena warna kabur (nge-blur) sebanyak 107.351 eksemplar, tidak register sebanyak 12.394 eksemplar, serta jenis misdruk berupa rusak karena terpotong berjumlah 11.791 eksemplar.

Berdasarkan diagram pareto, prioritas perbaikan yang perwan dilakukan oleh pembutan label $\mathrm{X}$ untuk menekan atau mengurangi jumlah produk cacat yang terjadi dalam produksi dapat dilakukan dengan mengurutkan persentase penyabab kecacatan tertinggi berturut-turut yaitu cacat karena warna kabur $(82 \%)$, tidak register $(9 \%)$ dan terpotong $(9 \%)$.

2. Berdasarkan data produksi yang diperoleh dari pembutan label $\mathrm{X}$ diketahui jumlah produksi pada bulan September 2012 adalah sebesar 1.329.968 eksemplar dengan jumlah produk cacat yang terjadi dalam produksi sebesar 131.536 eksemplar. Berdasarkan perhitungan, pembutan label X memiliki tingkat sigma 2.79 dengan kemungkinan kerusakan sebasar 98.831 untuk sejuta produksi (DPMO). Hal ini tentunya menjadi sebuah kerugian yang sangat besar apabila tidak ditangani sebab semakin banyak produk yang gagal dalam proses produksi tentunya mengakibatkan pembengkakan biaya produksi.

Saran

1. Secara umum penyebab utama terjadinya kerusakan atau misdruk berasal dari faktor manusia dan mesin. Oleh karena itu, usaha-usaha untuk mengatasi terjadinya misdruk yang disebabkan oleh faktor tersebut dapat dilakukan dengan cara sebagai berikut :

a. Manusia
Melakukan pengawasan atas para pekerja dengan lebih ketat.

Memberikan pelatihan kepada para pekerja.

> Membuat sistem penilaian kerja yang baru dengan tujuan untuk memotivasi kinerja para pekerja agar lebih baik.

b. Mesin

> Melakukan pengecekan kesiapan mesin sebelum dan sesudah digunakan agar sesuai standar operasional.

> Melakukan perawatan mesin secara berkala, tidak hanya ketika mesin mengalami kerusakan saja.

$>$ Segera mengganti komponen mesin yang rusak sehingga tidak menghambat proses produksi.

\section{DAFTAR PUSTAKA}

Ahyari, 1990. Manajemen Produksi. Yogjakarta : Edisi keempat. Jilid kedua. BPFE.

Assauri, Sofjan. 1998. Manajemen Operasi Dan Produksi. Jakarta : LP FE UI.

Budi Hermawan (2011). Manajeman Teori dan Terapan. Jurnal Pengaruh Kualitas Terhadap Kepuasan, Reputasi Merek Dan Loyaliats Konsumen Jamu Tolak Angin PT. Sido Muncul. Tahun 4, No. 2. Hal 9-17

Feigenbaum, Armand V, 2002. Kendali Mutu Terpadu. Jakarta : Edisi ketiga. Erlangga.

Gasperz, Vincent. 2005. Total Quality Management. Jakarta : PT. Gramedia Pustaka Utama.

Gasperz, Vincent. 2007. Lean Six Sigma. Jakarta : PT. Gramedia Pustaka Utama.

Heizer, Jay and Barry Render. 2006. Operations Management (Manajemen Operasi). Jakarta : Salemba Empat.

Vanany \& Desy Emilasari. (2011). Institute Teknologi Sepuluh November. Jurnal Aplikasi Six Sigma Pada Produk Clear File Di Perusahaan Stationary. 27-36.

Nasution, M. N.. 2005. Manajemen Mutu Terpadu. Bogor : Ghalia Indonesia.

Pande, Neumann, Roland R.Cavanagh.2002. The Six sigmaWay Bagaimana GE, Motorola \& Perusahaan Terkenal Lainnya Mengasah Kinerja Mereka. Yogjakarta : ANDI.

Pete \& Holpp. 2002. What Is Six Sigma. Yogjakarta : ANDI.

Prawirosentono, Suyadi. 2007. Filosofi Baru Tentang Manajemen Mutu Terpadu Abad 21 "Kiat Membangun Bisnis Kompetitif'. Jakarta : Bumi Aksara.

Pregiwati Pusporini \& Deny Andesta, (2011). Universitas Muhammadiyah Gersik. Jurnal Integrasi Model Lean Six Sigma Untuk Peningkatan Kualitas Produk. Hal 175-183

Reksohadiprojo, Soekanto \& Indriyo GitoSudarmo. 2000. Manajemen Produksi. Yogjakarta : Edisi keempat. BPFE.

Rony Prabowo, SE. ST. MT (2010). Institut Teknologi Adhi Tama Surabaya. Jurnal Analisa Peningkatan Kualitas Produk Keramik Dengan Menggunakan Metode Six Sigma Di Cv. Glassmico Tile Tulungagung. Hal 1-10 
Shanty Kusuma Dewi (2011). Universitas Muhammadiyah Malang. Jurnal Minimasi Defect Produk Dengan Konsep Six Sigma

Sugiharto (2011). Universitas Kreisten Petra. Juarnal Six Sigma, Perangkat Manajerial Perusahaan pada Era Ekonomi Baru.

Sukma Prayisno. (2011). Universitasa Gunadarma. Perbaikan Kualitas Dudukan Jok Motor Dengan Metode Enam Sigma

Sugiyono. 2004. Metode Penelitian Bisnis. Bandung : CV Alfabeta

Widhy Wahyani. (2010). Institut Teknologi Adhi Tama Surabaya. Jurnal. Peranan DMAIC Dalam Mengurangi Jumlah Produk Cacat 